

\title{
Influence of sliding contact local dynamics on macroscopic friction coefficient variation
}

\author{
Laurent Baillet, S. d'Errico, Yves Berthier
}

\section{To cite this version:}

Laurent Baillet, S. d'Errico, Yves Berthier. Influence of sliding contact local dynamics on macroscopic friction coefficient variation. Revue Européenne des Éléments Finis, 2005, 14 (2-3), pp.305 à 321. 10.3166/reef.14.305-321 . insu-00355347

\section{HAL Id: insu-00355347 https://hal-insu.archives-ouvertes.fr/insu-00355347}

Submitted on 22 Jan 2009

HAL is a multi-disciplinary open access archive for the deposit and dissemination of scientific research documents, whether they are published or not. The documents may come from teaching and research institutions in France or abroad, or from public or private research centers.
L'archive ouverte pluridisciplinaire $\mathbf{H A L}$, est destinée au dépôt et à la diffusion de documents scientifiques de niveau recherche, publiés ou non, émanant des établissements d'enseignement et de recherche français ou étrangers, des laboratoires publics ou privés. 


\title{
Influence of sliding contact local dynamics on macroscopic friction coefficient variation
}

\author{
Laurent Baillet — Salvatore D'Errico — Yves Berthier \\ * Laboratoire de Mécanique des Contacts et des Solides, CNRS-UMR 5514 \\ INSA de Lyon, 69621 Villeurbanne Cedex, France \\ e-mail: laurent.baillet@insa-lyon.fr
}

\begin{abstract}
The aim of this paper is to present a means of analysing "friction instabilities". The explicit dynamic finite element software PLAST3 in 3D is used to simulate the behaviour of the two bodies (pin and disk) of a tribometer during frictional contact. Coulomb's friction law is used at the contact surface.

The phenomenon of relay between the instantaneous contact zone, the contact stresses distribution and the kinematics of the contact surfaces are presented. As the friction coefficient and velocity of the disk are considered constants in the simulations, the contact zone (stick, slip) and separation depend on a "dynamic effect". This generates wave propagation in the interface and involves a variation of normal contact stress.

Definitions of macroscopic and local friction coefficients are given. The interfacial instabilities due to the dynamic effect produce a macroscopic friction coefficient that is less than the local friction coefficient. The influence of disk velocity on the macroscopic friction coefficient is also investigated.
\end{abstract}

RÉSUMÉ. Le but de ce papier est d'analyser les instabilités dues au frottement. Le code de calcul par éléments finis en formulation explicite dynamique PLAST3 est utilisé pour la simulation en $3 D$ du contact frottant d'un pion sur un disque en rotation. Une loi de type Coulomb est appliquée au niveau de l'interface.

L'étude de la variation des zones en contact, de la distribution des contraintes de contact et de la cinématique des surfaces de contact est menée. Le coefficient de frottement et la vitesse de rotation étant constants, la distribution des zones du pion en contact (glissant, adhérent) ou séparées du disque dépend d'un "effet dynamique ». Celui-ci génère à l'interface une onde qui se propage en faisant varier les contraintes de contact normales.

Les définitions du coefficient de frottement macroscopique et local sont données. Il est montré numériquement que la présence d'instabilités au niveau du contact donne un coefficient de frottement macroscopique inférieur au coefficient de frottement local imposé. La variation de ce coefficient de frottement macroscopique est étudié en fonction de la vitesse de rotation

MOTS-CLÉS : Frottement, Contact, Instabilités, Eléments finis, Dynamique, Vibration.

KEYWORDS: Friction, Contact, Instabilities, Finite Element, Dynamic, Vibration.

Revue européenne des éléments finis. Volume $\mathrm{X}-\mathrm{n}^{\circ} \mathrm{X} / 2005$, pages 1 à $\mathrm{X}$ 


\section{Introduction}

Contact of mechanical parts with friction remains a major topic of research. As soon as two bodies in contact are subjected to a relative motion, a friction force is generated at the interface in opposition to this motion. This friction force, which among other things, depends on the mechanical characteristics of the two bodies in contact, their relative velocity, the load, the presence of a third body, and the mechanisms containing the contact, plays an important role in the behaviour and efficiency of mechanisms. For example, in a brake device, we seek to obtain a stable and, if possible, high friction coefficient in order to avoid excessive wear, the generation of noise and, more generally, vibrations (Abendroth et al., 2000).

The phenomenon of vibrations caused by friction has been studied since the 1930s (Mills, 1938). Brockley (Ko et al., 1970) (Brockley et al., 1970) classified vibrations caused by friction into two categories: stick - slip and quasi-harmonic oscillations. These two categories most often correspond to a difference in the macroscopic relative velocities of the two bodies in contact. Many theories, models and experimental tests have attempted to explain the generation of vibrations by the dependency of the friction coefficient on velocity. On the one hand, some authors have observed that instabilities are generated when the friction coefficient decreases with velocity (Bo et al. , 1982) (Van De Velde et al., 1998) while others have observed that the more velocity is reduced, the more marked the generation and magnitude of these vibrations becomes. Recently, analytical studies by Adams (Adams 1995, 1998), Simões and Martins (Simões et al., 1998), Rice and Ranjith (Rice et al., 1983), (Ranjith et al., 2001), Nguyen (Nguyen, 2003), and numerical studies by Oueslati (Moirot et al., 2003) (Oueslati et al., 2003) and Baillet (Baillet et al., 2002) on contact dynamics with friction, have shown that the instabilities that generate noises and vibrations can occur with a Coulomb type constant friction coefficient at the interface (non-dependent on velocity). Another important aspect of vibrations caused by friction is the variation of tangential force due to the variation of the normal force of the contact. This coupling between normal and tangential forces was studied by Tolstoi (Tolstoi, 1967), Godfrey (Godfey et al., 1967) and Budanov (Bundanov et al., 1980).

In practice, modelling vibrations caused by friction is a multi-scale problem, since it involves both space and time. Indeed, phenomena of very small scale in length and time (microscopic contact in the region of several $\mu \mathrm{m}$ and vibrations at high frequencies) interact significantly with larger scale phenomena (modification of contact geometry due to both wear and the dynamics of the components). A large panorama of vibration dynamics caused by friction and several phenomena related to mechanical systems were presented by Ibrahim (Ibrahim, 1994). Akay (Akay, 2002) presented a global view of friction acoustics by focusing on different aspects such as friction noises, the vibrations and waves in solids caused by friction and the 
description of other friction phenomena related to acoustics (noises produced by insects).

All these works devoted to enriching knowledge of vibrations caused by friction show that this complex physical phenomenon has still not been completely understood. Indeed, little is understood of friction mechanisms that start in a simple mechanism such as a tribometer and the different couplings that link the elements of the tribological triplet (Berthier, 2001) (Descartes et al., 2002). These elements are the mechanism, the first bodies (disk, pin) and the third body (wear particles trapped in the contact) (Iordanoff et al., 2002). The main problem in experiments is the limited resolution of tools intended to measure contact stresses, relative velocity, and the temperature and flow of the third body. A way of overcoming this problem is to use numerical models of the contact in order to understand local dynamic conditions.

The first part of this paper is devoted to presenting the finite element software PLAST3 (developed at LaMCoS), used to formulate the numerical models. The explicit dynamic formulation and time scheme of this software allow the reproduction of transient phenomena generated at the interface. This software includes contact and friction algorithms based on the formulation of Lagrangian multipliers.

The second part is devoted to studying local contact dynamics at mechanical scale, i.e. at micrometer scale. The numerical study of a tribometer composed of a pin and a disk are performed. The third body is substituted by a Coulomb type friction coefficient. These models highlight the generation of instabilities due to a "dynamic effect" of the two bodies that occurs at the contact surface by the propagation of stick - slip, slip - separation or stick - slip - separation type waves. This propagation leads to a variation of the normal contact stress. These vibrations generated in the contact then propagate in the mechanism. Certain parts can generate acoustic pressures that in turn generate audible noises.

The last part of the paper is devoted to studying the variation of the macroscopic friction coefficient (ratio between the tangential force and the normal force exerted on the pin) as a function of the macroscopic relative velocity. It is this macroscopic friction coefficient that is measured on a tribometer. During the study, the local friction coefficient imposed on the contact surface of the disk and pin is constant, therefore non-dependent on velocity. The progression of macroscopic friction with velocity was studied analytically by Adams in 2D (Adams, 1998). Adams considered the waves of a stick-slip type contact. In this article, for high velocities, the propagation of waves generating the separation of contact surfaces is taken into account and allows using all the spectrums of the macroscopic relative velocities. Numerically, the progression of the macroscopic friction coefficient is analysed for different local friction coefficient values exerted on the contact surface of the disk and pin. 


\section{Temporal study of the phenomenon with PLAST3}

The explicit dynamic finite element code PLAST3 in 3D (Baillet et al., 2002) is used to simulate the behaviour of the bodies (pin and disk) during frictional contact. PLAST3 is designed for large deformations, non-linear material behaviour and uses a forward Lagrange multiplier method (Carpenter et al., 1991) for the contact treatment between deformable bodies. For the dynamic study, the formulation is both spatially discretized using the finite element method and temporally discretized using the $\beta_{2}$ method. The contact algorithm uses slave nodes (situated on the pin contact surface) and target surfaces (on the disk) described by four-node quadrilateral elements, as the $3 \mathrm{D}$ element used is an isoparametric hexahedron. An elementary target surface defined by four nodes is broken down into a bi-cubic Ferguson patch with $\mathrm{C}^{1}$ continuity across the adjacent boundary (Baillet et al., 2002).

The forward increment Lagrange multiplier method equation set is constructed using the equations of motion developed via the principle of virtual work equation at time step $t_{n} \quad\left(t_{n}=n \Delta t\right)$ and the displacement constraints acting on the surfaces in contact at time $t_{n+1}$

$$
\left\{\begin{array}{l}
\mathbf{M} \ddot{\mathbf{u}}_{n}+\mathbf{K} \mathbf{u}_{n}+\mathbf{G}_{n+l}^{\mathrm{T}} \boldsymbol{\lambda}_{n}=\mathbf{r}_{n} \\
\mathbf{G}_{n+l}\left\{\mathbf{x}_{n}+\mathbf{u}_{n+1}-\mathbf{u}_{n}\right\} \leq \mathbf{0},
\end{array}\right.
$$

where $\lambda_{n}$ is the contact force vector acting on the nodes of the slave surface, $\mathbf{G}_{n+1}$ is the global assembled matrix of the constraint elementary matrices, $\mathbf{x}_{n+1}=\mathbf{x}_{n}+\mathbf{u}_{n+1}-\mathbf{u}_{n}$ is the coordinate vector at time $t_{n+1}, \mathbf{M}$ is the mass matrices, $\mathbf{r}_{n}$ the nodal vectors of external forces. At any time step, the velocity $\dot{\mathbf{u}}_{n}$ and acceleration $\ddot{\mathbf{u}}_{n}$ vectors are related to displacements and time increment $\Delta t$ following the $\beta_{2}$ method $\left(\beta_{2} \in[0.5 ; 1)\right.$

$$
\left\{\begin{array}{l}
\ddot{\mathbf{u}}_{n}=\frac{2}{\Delta t^{2}}\left(\mathbf{u}_{n+1}-\mathbf{u}_{n}-\Delta t \dot{\mathbf{u}}_{n}\right) \\
\dot{\mathbf{u}}_{n}=\frac{1}{1+2 \beta_{2}}\left\{\dot{\mathbf{u}}_{n-1}+\Delta t\left(1-\beta_{2}\right) \ddot{\mathbf{u}}_{n-1}+\frac{2 \beta_{2}}{\Delta t}\left(\mathbf{u}_{n+1}-\mathbf{u}_{n}\right)\right\} .
\end{array}\right.
$$

The classical central difference scheme can be found using $\beta_{2}=0.5$. The new coordinates $\mathbf{x}_{n+1}^{*}=\mathbf{x}_{n}+\mathbf{u}_{n+1}^{*}-\mathbf{u}_{n}$ of the nodes situated on the contact surfaces (pin and disk) are first computed with $\lambda_{n}$ equal to zero. If $\beta_{2}=0.5$, the nodal displacements at time $t_{n+1}^{*}$ are obtained as

$$
\mathbf{u}_{n+l}^{*}=\Delta t^{2} \mathbf{M}^{-1}\left(\mathbf{r}_{n}-\mathbf{K} \mathbf{u}_{n}\right)+2 \mathbf{u}_{n}-\mathbf{u}_{n-1}
$$


An elementary constraint matrix is created for each slave node that has penetrated through a target surface. The global assembled matrix $\mathbf{G}_{n+1}$ enables the calculation of the contact forces $\lambda_{n}$ and the coordinates $\mathbf{x}_{n+1}$

$$
\left\{\begin{array}{l}
\lambda_{n}=\left\{\Delta t^{2} \mathbf{G}_{n+1} \mathbf{M}^{-1} \mathbf{G}_{n+1}^{\mathrm{T}}\right\}^{-1} \mathbf{G}_{n+1}\left(\mathbf{x}_{n}+\mathbf{u}_{n+1}^{*}-\mathbf{u}_{n}\right) \\
\mathbf{u}_{n+1}=\mathbf{u}_{n+1}^{*}-\left(\Delta t^{2} \mathbf{M}^{-1} \mathbf{G}_{n+1}^{\mathrm{T}} \boldsymbol{\lambda}_{n}\right)
\end{array}\right.
$$

The equations [4] are solved using Gauss - Seidel method. As no bonding and a standard Coulomb friction law are considered on each slave node, the contact conditions during each internal iteration of this method are expressed as:

$$
\begin{aligned}
& \lambda_{n}^{\overrightarrow{\mathrm{n}}} \leq \mathbf{0} \quad \text { (Contact) } \\
& \| \lambda_{n}^{\overrightarrow{\mathrm{t}} \|}|\leq \mu| \lambda_{n}^{\overrightarrow{\mathrm{n}}} \mid \\
& \quad \text { if }\left\|\lambda_{n}^{\overrightarrow{\mathrm{t}}}\right\|<\mu\left|\lambda_{n}^{\overrightarrow{\mathrm{n}}}\right|, \quad v_{t}=0 \quad \text { (stick) } \\
& \text { - if }\left\|\lambda_{n}^{\overrightarrow{\mathrm{t}}}\right\|=\mu\left|\lambda_{n}^{\overrightarrow{\mathrm{n}}}\right|, \quad \lambda_{n}^{\overrightarrow{\mathrm{t}}} \cdot v_{t} \leq 0 \quad \text { (slip), }
\end{aligned}
$$

where $v_{t}$ is the relative tangential velocity of a slave node related to the target surface, and $\vec{n}$ and $\vec{t}$ are the normal and tangential vectors defining the contact. The friction law used here is the standard Coulomb friction model without regularisation of the tangential stress with respect to the tangential velocity component. It should be noted that Simões (Simões et al., 1998), Ranjith (Ranjith et $a l ., 2001)$ used a regularized law for the analytical calculations.

\section{Simulation of the pin - disk contact with friction}

The phenomena of instability generated in the contact between two deformable bodies (pin and disk) is analysed by using the PLAST3 software. The tribometer model chosen is shown in figure 1a,b.

At the beginning, an increasing force $\mathrm{F}$ is applied in direction $\mathrm{z}$ until it reaches a pre-selected value corresponding to a uniformly normal displacement on the top of the pin. Application of this force brings the pin into contact friction with the disk, which rotates at constant applied velocity $\omega$. The two deformable bodies have smooth surfaces (roughness and superficial imperfections are neglected). Thermal and physicochemical effects are not taken into account. 


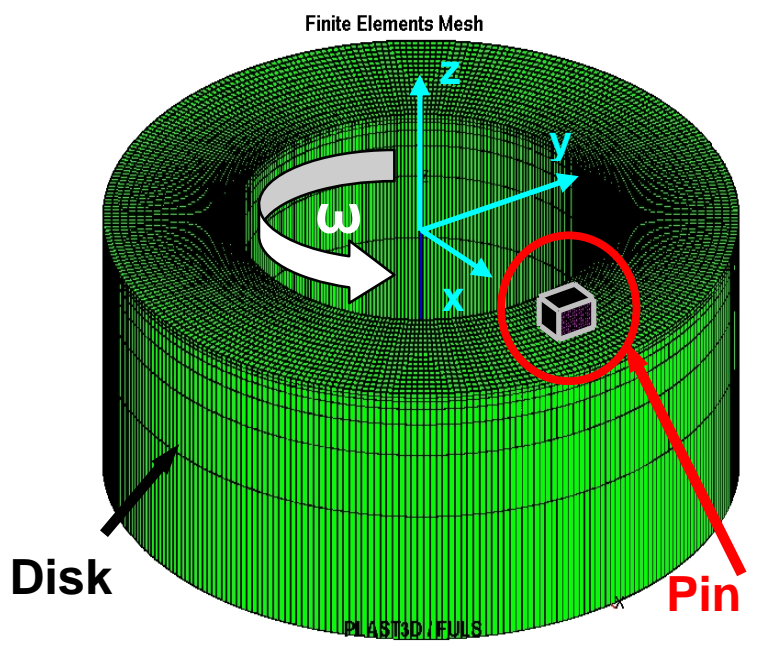

a)

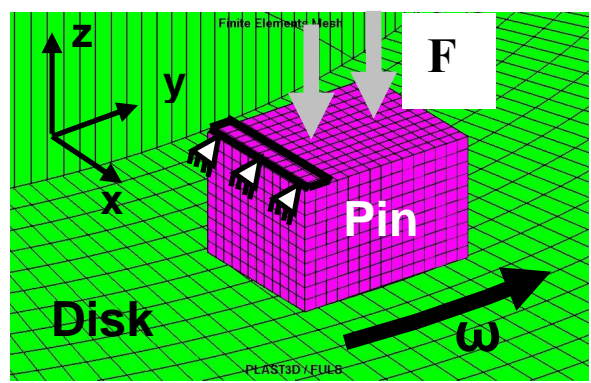

b)

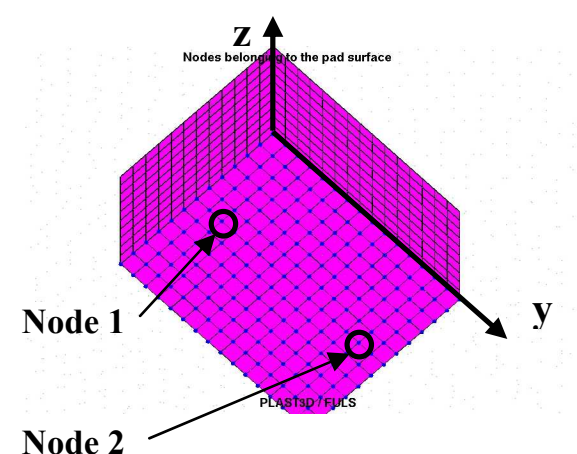

c)

Figure 1. a) Finite element mesh of pin friction on a disk; b) boundary conditions imposed on the pin; c) the nodes studied belonging to the pin surface contact.

The characteristics of the two bodies in contact are given in table 1 .

\begin{tabular}{lcc}
\hline & Disk & Pin \\
\hline Young's modulus $E[\mathrm{MPa}]$ & 210000 & 1000 \\
\hline Poisson's coefficient $v$ & 0.3 & 0.3 \\
\hline Density $\rho[\mathrm{Kg} / \mathrm{m} 3]$ & 7800 & 2500 \\
\hline Interior radius $r_{i}[\mathrm{~mm}]$ & 70 & \\
\hline Exterior radius $r_{e}[\mathrm{~mm}]$ & 120 & \\
\hline Thickness $e[\mathrm{~mm}]$ & 85 & $12 \times 15 \times 10$ \\
\hline Width $(\mathrm{x})$, length $(\mathrm{y})$, height $(\mathrm{z})[\mathrm{mm}]$ & & \\
\hline
\end{tabular}

Table 1. Characteristics of the disk and pin. 
The boundary conditions considered are the following:

normal force $\mathrm{F}$ is applied to all the nodes of the upper surface of the pin;

the nodes of the first two lines of the pin's upper surface are blocked in the $\mathrm{x}$ and $y$ directions (figure $1 \mathrm{~b}$ );

the nodes of the interior radius of the disk are blocked in the $\mathrm{z}$ direction and have imposed rotational velocity $\omega$.

The kinematics characteristics (trajectories, cycles in the phase's plan etc.) and dynamics (normal and tangential contact stresses) for two nodes belonging to the pin contact surface (figure 1c) are dealt with later in the paper.

\section{Results and discussion}

For each time simulation, bringing the pin into contact with the disk leads to a transient state. As the rotation of the disk and the force applied to the pin are constant, this state then becomes stable or "unstable" according to the value of the parameters (velocity, load, friction, material, boundary conditions, etc.) chosen for the simulation. A stable state is characterised by a contact surface where all the nodes of the pin slide on the surface of the rotating disk. An "unstable" state is characterised by the formulation of zones in contact (slip or stick) at the pin surface and zones separated from the surface of the disk. In the case where the state is "unstable", a time period related to the distribution of the mechanical volume and surface magnitudes is established. The periodic steady state will be dealt with later in the paper. This article does not focus on the stable state, thus the curves presented as a function of time are those obtained during the periodic steady state.

\subsection{Kinematics and dynamics of the contact surface}

The simulation parameters are described in table 2. These parameters generate stick - slip - separation (Baillet et al., 2002) (Linck et al., 2003) type waves at the surface of the contact between the pin and disk.

\begin{tabular}{ll}
\hline Coulomb friction coefficient $\mu$ & 0.4 \\
\hline Normal load $F[\mathrm{~N}]$ & 30 \\
\hline Equivalent normal stress on the top $[\mathrm{MPa}]$ & 0.167 \\
\hline Velocity of the disc $\omega[\mathrm{rpm}]$ & 7 \\
\hline Simulation time step $\Delta t[\mathrm{~s}]$ & $0.55^{*} 10^{-7}$
\end{tabular}

Table 2. Simulation parameters 
The linear velocity of the disk at the two nodes (figure 1c) is about $67 \mathrm{~mm} / \mathrm{s}$ in direction $\mathrm{y}$. The displacements in the three directions and the velocity in direction $\mathrm{y}$ of node 1 as a function of time are shown in figure 2a. The displacement curve in direction y is characteristic of a stick-slip type wave with a magnitude of $2 \mu \mathrm{m}$. In direction $\mathrm{z}$, node 1 is in contact with the surface of the disk when $\mathrm{z} \leq-1 \mu \mathrm{m}$. This node separates by $0.15 \mu \mathrm{m}$ from the surface of the disk at a frequency of about $14500 \mathrm{~Hz}$.

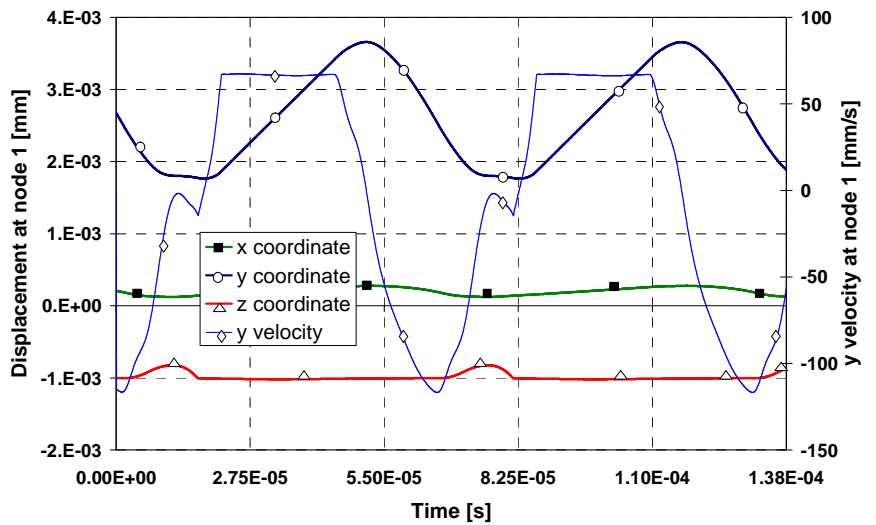

a)



b)

Figure 2. a) Displacements in the three directions and velocity y, b) Equivalent friction coefficient $\mu_{1 e q}$ and velocity y of node 1 versus time. 
The equivalent friction coefficient $\mu_{1 \mathrm{eq}}$. at node 1 is defined by

$$
\mu_{\text {leq. }}=\left|\tau_{1} / \sigma_{\mathrm{n} 1}\right|
$$

where $\tau_{1}$ and $\sigma_{\mathrm{n} 1}$ are respectively the stress of the tangential and normal contact at node 1 . This equivalent friction coefficient allows to know the different states (stick, slip, separation) of the surface near node 1 (figure $2 b$ ) as a function of time.

When $\mu_{\text {leq. }}$. is equal to 0.4 , node 1 is in slip state. When $\mu_{\text {leq. }}<0.4$, the node sticks to the surface of the disk and its velocity in direction $\mathrm{y}$ is about $67 \mathrm{~mm} / \mathrm{s}$. A null value of $\mu_{\text {leq. }}$. corresponds to the separation of the node from the surface of the disk, thus canceling the contact stresses. The surface of the area close to node 1 therefore describes a limit cycle constituted by phases of contact (slip-stick-slip) and separation of the disk surface (figure $2 b$ ). Since the contact surface of the pin is small (Baillet et al., 2005), this limit cycle is obtained with the same frequency $(\mathrm{f}=14500 \mathrm{~Hz}$ ) whatever the considered contact zone.

Figure 3 a represents the trajectories (in the plane $y-z$ ) of the nodes belonging to the contact surface of the pin. The limit cycles are all traveled in trigonometric direction. The nodes are in contact with the surface of the disk when the coordinate in direction $\mathrm{z}$ is less than $-1 \mu \mathrm{m}$. The maximum local separation of the two surfaces of the contact is about $0.3 \mu \mathrm{m}$. Obviously, this value can be amplified by choosing other materials and boundary conditions (Baillet et al., 2005). It should be noted that locally, the contact surface can deform sufficiently, so no stresses is transmitted.

On figure ( $3 b)$, the phase-plan diagram allows the observation of the different states (contact or separation) of the nodes of the contact surface (cf. figure 1c) during a limit cycle. The horizontal line $(v=67 \mathrm{~mm} / \mathrm{s})$ corresponds to the sticking part and the curves below $(v<67 \mathrm{~mm} / \mathrm{s})$ represent the slip and stick states that can be determined in figure $3 \mathrm{a}$. For the nodes located at the front of the contact (node 1), when the contact occurs, the relative velocity in comparison to the disk is about $70 \mathrm{~mm} / \mathrm{s}$, whereas it is about $210 \mathrm{~mm} / \mathrm{s}$ for the nodes at the rear (node 2) of the contact. These relative velocities in the contact are therefore much higher than the macroscopic relative velocity $(67 \mathrm{~mm} / \mathrm{s})$.

\subsection{Dynamic effect}

Since the Coulomb friction coefficient and the velocity of the disk are constants during the simulation, the stick, slip and separation zones therefore depend on a "dynamic effect" that is a function of mechanical behaviour, the geometry of the two bodies in contact and the boundary conditions. This effect generates the propagation of waves at the contact surface leading to a variation of the normal contact stress. This coupling between volume and surface strongly depends on the value of the local friction coefficient, the macroscopic relative velocity of the contact and the Poisson coefficient of the bodies in contact (Baillet et al., 2005). 
10 Revue européenne des éléments finis. Volume $\mathrm{X}-\mathrm{n}^{\circ} \mathrm{X} / 2005$

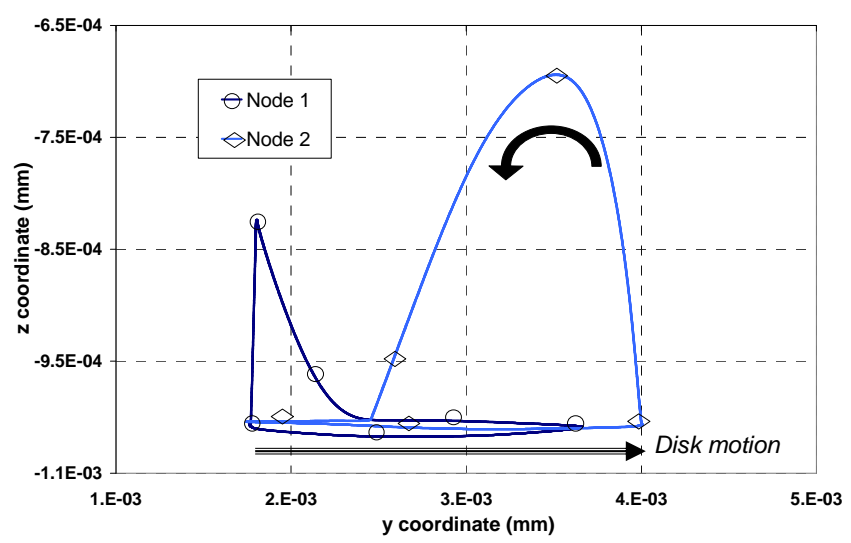

a)

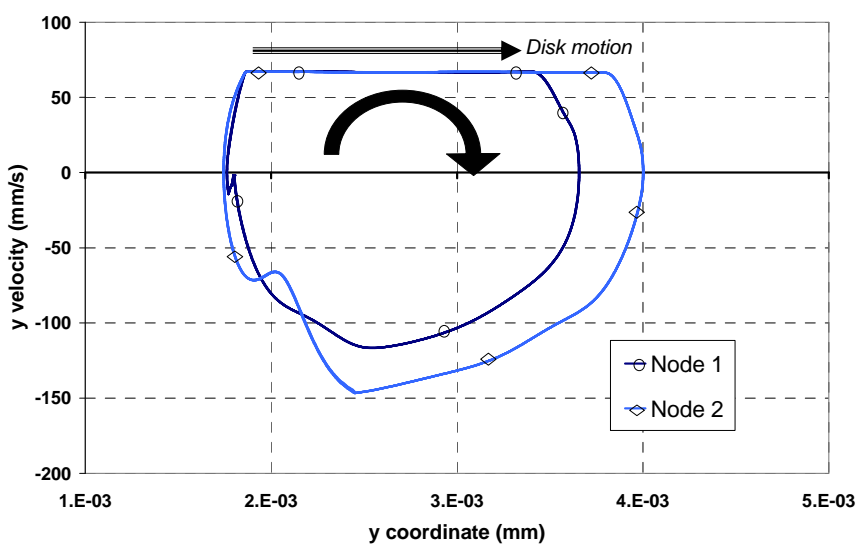

b)

Figure 3. a) Trajectories in plane $y-z$, b) phase-plane diagram, of the nodes ( $f$. figure 1c) belonging the pin contact surface.

Figure 4 shows the velocity in direction $y$ and the normal contact stress $\sigma_{\mathrm{n} 1}$ at node 1 (fig.1c). When the node enters into contact with the disk $\left(t=t_{\mathrm{A}}\right)$, its normal stress increases, causing the node to change from slip $\left(t \in\left[t_{A}, t_{B}\right]\right)$ to stick state $\left(t \in\left[t_{B}, t_{D}\right]\right)$. Normal stress then occurs at a maximum of $0.5 \mathrm{MPa}\left(t=t_{C}\right)$. It should be noted that this value is higher than the normal pressure (table 2) applied on the upper surface of the pin. Since the normal stress $\sigma_{n 1}$ decreases $\left(t>t_{C}\right)$, the node returns to slip state $\left(t \in\left[t_{D}, t_{E}\right]\right)$ by reaching a relative velocity in direction $y$ of about $180 \mathrm{~mm} / \mathrm{s}$ before separating $\left(t>t_{E}\right)$ from the disk surface. This local dynamic effect is the consequence of a global dynamic effect of the bodies in contact (figure 5). 


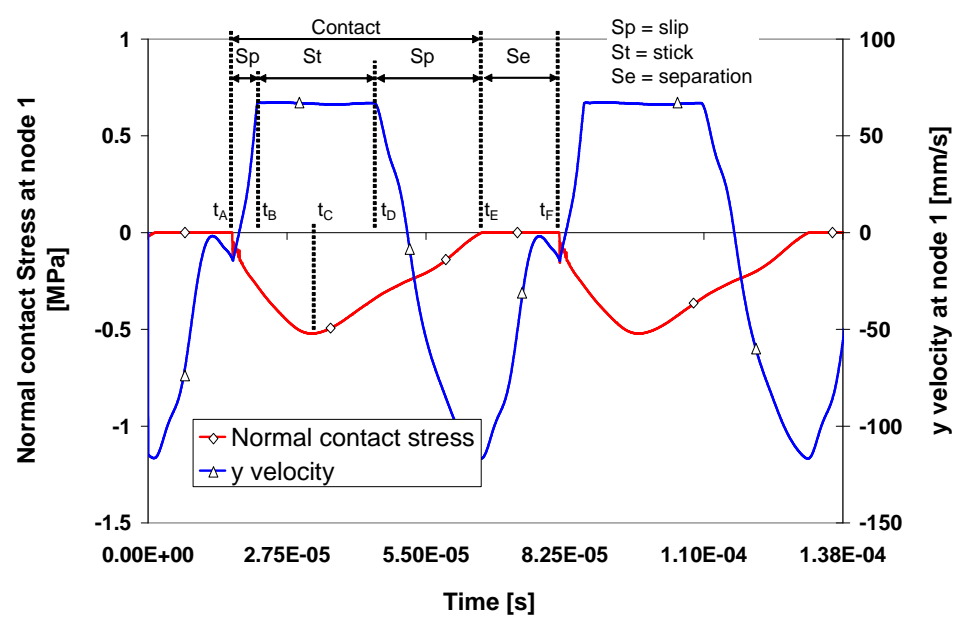

Figure 4. Normal contact stress $\sigma_{\mathrm{n} 1}$ and y velocity versus time

The contact forces at the nodes of the pin (right column on fig.5) and the distribution of velocities in the volume (left column on fig.5) of the pin for four different instants of a cycle during the periodic steady state are represented in figure 5. These four snapshots visualizes the dynamic effect constituted by the coupling between the dynamic field of the velocities in the pin and the distribution of the normal and tangential contact forces, i.e. the local state at the contact surface.

In figure $5 \mathrm{a}$, the distribution of the velocity field in the pin is opposed to $\mathrm{z}$ at the rear of the contact. The pin contact surface will therefore enter into contact with the disk from the rear to the front. A wave is propagated towards the front of the contact by changing the node from slip to stick state $\left(t \in\left[t_{A}, t_{B}\right]\right)$. During the stick state $\left(t \in\left[t_{B}, t_{D}\right]\right)$, the maximum value of the normal stress $\left(t=t_{C}\right)$ corresponds to a velocity field in the pin in the direction opposite to $\mathrm{z}$ (figure 5.b). The inversion of this velocity field $\left(t>t_{C}\right)$ then causes a reduction of normal contact stress. Since the tangential stress remains almost constant, the contact surface changes from stick to slip state $\left(t \in\left[t_{C}, t_{E}\right]\right)$ (figure $5 c$ ). This change of status occurs from the rear to the front of the pin. As the velocity field in the pin follows direction $\mathrm{z}$ (figure $5 \mathrm{~d}$ ), the normal contact stress continues to decrease $\left(t \in\left[t_{D}, t_{E}\right]\right)$ and generates a wave from the rear to the front of the pin, causing the contact surface to change from slip to separated state $\left(t \in\left[t_{E}, t_{F}\right]\right)$ (figure $5 d$ ).

This dynamic effect is the reason for the normal contact stress values $\left(\left|\sigma_{\mathrm{n} 1}\right|>\right.$ $0.55 \mathrm{MPa}$ on figure 4) being higher than the theoretical calculated value $(0.167$ $\mathrm{MPa})$ and for the relative slip velocities $(\approx 180 \mathrm{~mm} / \mathrm{s})$ being higher than the macroscopic linear velocity of the disk $(67 \mathrm{~mm} / \mathrm{s})$. These local values of tangential stresses and relative velocities are therefore much higher than those imposed macroscopically and therefore need to be taken into account in studies of surface degradation and thus wear. 




Figure 5. Pin velocity vectors, contact force vectors, contact node status (blue = stick; green = slip; red = separation) for the four different times (figure 4), a) $\left.\left.\left.\mathrm{t} \in\left[\mathrm{t}_{\mathrm{A}}, \mathrm{t}_{\mathrm{B}}\right], b\right) \mathrm{t} \in\left[\mathrm{t}_{\mathrm{C}}, \mathrm{t}_{\mathrm{E}}\right], c\right), \mathrm{t} \in\left[\mathrm{t}_{\mathrm{D}}, \mathrm{t}_{\mathrm{E}}\right] d\right) \mathrm{t} \in\left[\mathrm{t}_{\mathrm{E}}, \mathrm{t}_{\mathrm{F}}\right]$. 


\subsection{Local and macroscopic friction coefficient}

On the basis of numerical simulations of a tribometer, the aim of this part is to make a numerical comparison of local and macroscopic friction values. The variation of the macroscopic friction coefficient with the rotation velocity of the disk is studied. We define the macroscopic friction coefficient as the ratio between the tangential force $(\mathrm{T})$ and normal force $(\mathrm{F})$ exerted on the pin (figure 6). These forces are therefore measured far from the contact and correspond to those measured on a tribometer. The local friction coefficient is constant and equal to Coulomb's friction coefficient imposed at the nodes of the contact surface (figure 6). The local friction coefficient $\mu$ is therefore a datum used in modelling the tribometer, whereas the macroscopic friction coefficient $\mu^{*}$ is a variable calculated during the periodic steady state.

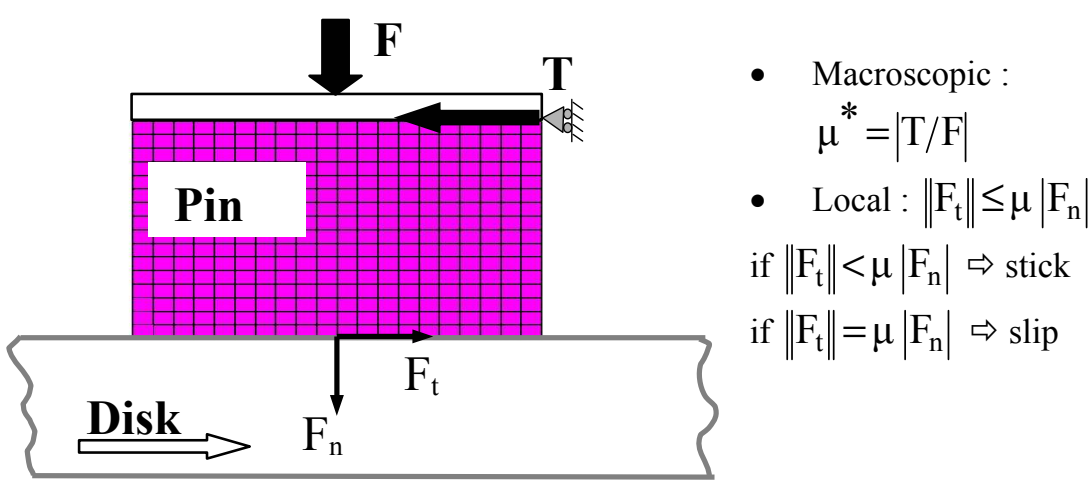

Figure 6. Illustration of local and macroscopic friction coefficient.

In the case of a contact with friction in 2D between two semi-infinite halfspaces, Adams (Adams, 1998) demonstrated analytically that in the presence of stick-slip type instabilities, the macroscopic friction coefficient $\left(\mu^{*}\right)$ decreased when the macroscopic relative velocity increased. Tribometer simulations (figure 1a) were performed varying the disk rotation velocity for different values of the local friction coefficient $\mu$ defined between the disk and the pin. As force $\mathrm{F}$ is constant during the steady state, calculation of the tangential force far from the contact (figure 6) allows calculating the macroscopic friction coefficient (figure 7). For the tribometer studied, the state is stable (contact surface in slip state) when the local friction coefficient $\mu$ is less than or equal to 0.2 . In these cases $(\mu \leq 0.2)$, coefficients $\mu^{*}$ and $\mu$ are equal. When $\mu$ is strictly higher than 0.2 , the instabilities generated at the contact give rise to a periodic steady state. The types of these instabilities depend on the rotation velocity of the disk and are described below. 
For low rotation velocities $(\omega \leq 6 \mathrm{rpm})$, instabilities at the interface are of stick - slip type and the macroscopic friction coefficient increases as velocity increases (figure 7).

For disk rotation velocities higher than $6 \mathrm{rpm}$, the contact surfaces of the disk and pin separate locally and the instability generated is of stick - slip - separation type. For higher velocities $(\omega \geq 35 \mathrm{rpm})$, the instabilities are of slip - separation type. For velocities higher than $6 \mathrm{rpm}$, the macroscopic friction coefficient increases with velocity.

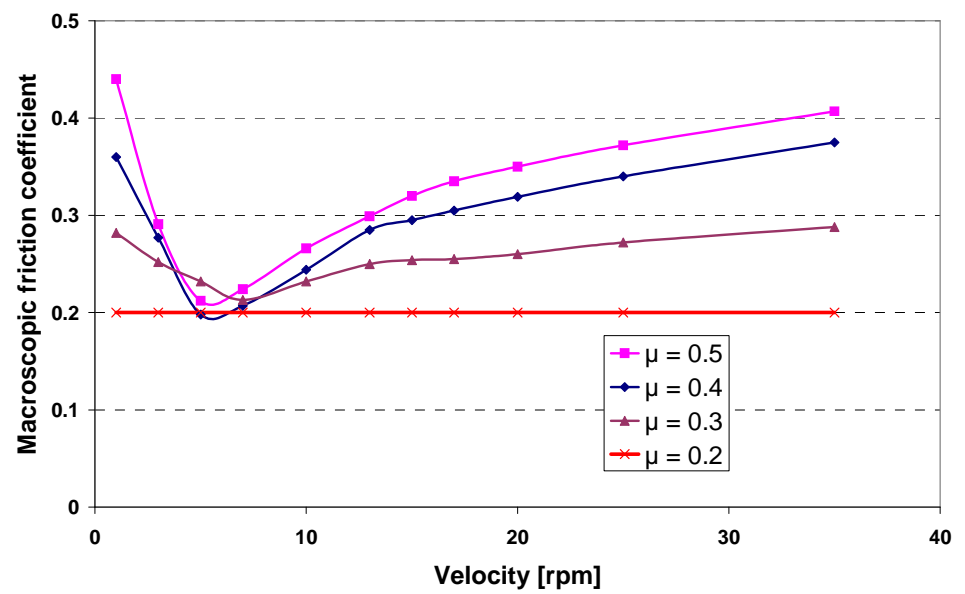

Figure 7. Macroscopic friction coefficient versus disk velocity for different local friction coefficients.

Figures $8 \mathrm{a}$ and $8 \mathrm{~b}$ link the phenomena occurring in the contact with the variation of the macroscopic friction coefficient as a function of the disk rotation velocity. These figures show a one and a half limit cycle of the normal and tangential stresses at node 1 (figure 1c) during the periodic steady state. The frequency of a limit cycle $(\mathrm{f}=14500 \mathrm{~Hz}$ ) is not affected by the change of velocity (Baillet et al., 2005).

From 0 to $6 \mathrm{rpm}$, tangential contact stress $\tau_{1}$ (figure 8b) have a small variation during the stick phase. However, increasing velocity leads to an increase of normal contact stress $\sigma_{\mathrm{n} 1}$ (figure 8a). The latter becomes maximal during the stick phase (figure 4). The ratio $\left|\tau_{1} / \sigma_{\mathrm{n} 1}\right|$ on each zone of the contact surface thus decreases when velocity changes from 0 to $6 \mathrm{rpm}$. This local phenomenon is the cause of the reduction of the macroscopic friction coefficient for disk rotation velocities lower than $6 \mathrm{rpm}$.

For velocities higher than $6 \mathrm{rpm}$ during a limit cycle, the stick phase decreases while the separation phase increases. It is this decrease in stick time that is the cause of the increase of macroscopic friction coefficient. For high velocities, the latter tends to take a lower value towards the imposed local friction coefficient (figure 7). 


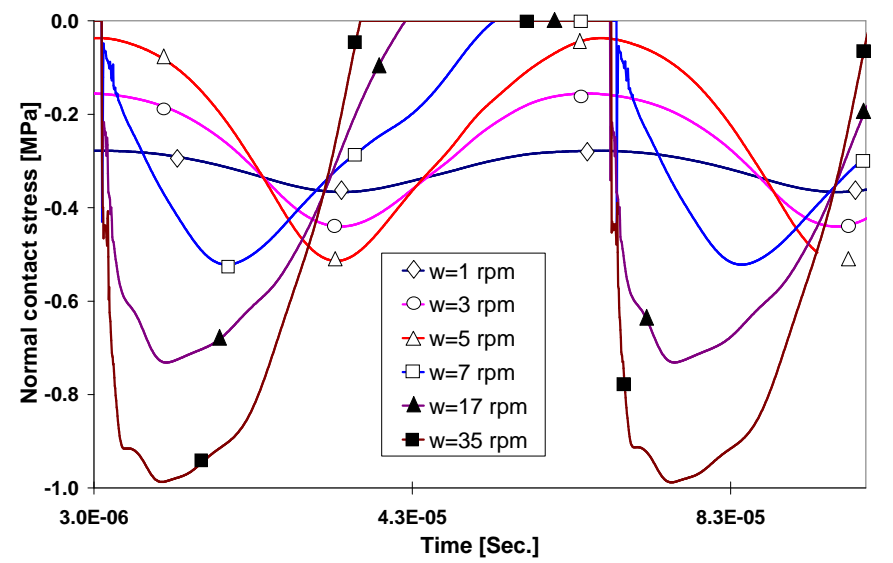

a)

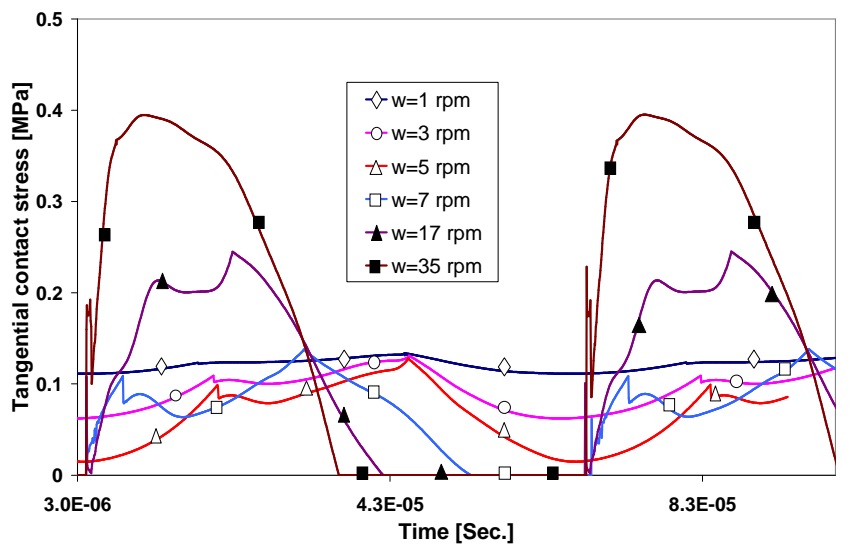

b)

Figure 8. a) Normal (a) and tangential (b) contact stresses at node 1 versus time and for different disk velocities.

\section{Conclusions}

At mechanical scale $(\mu \mathrm{m})$, the numerical simulation of a pin/disk tribometer allows to study the local phenomena involved at the surface of the pin contact. The dynamic coupling between the volume and surface of the pin leads to a contact surface composed locally of zones in contact and separated zones. The zones in contact subdivide into stick and slip zones. Consequently, only the surface in contact is subjected to the action of local friction. Thus it is only this surface that "transmits" 
to the pin the macroscopic tangential force measured far from the contact, that is to say measured physically by the tribometers. This explains that even for the same local friction applied over the entire surface, global friction can be less than or equal to local friction. A consequence of this is that since the dynamic geometry and the global friction are linked to velocity, though it is not a intrinsic "friction/velocity" phenomenon, merely an effect of "variation of the active surface". Lastly, this dynamic geometry leads to local velocities and stresses higher than the average stresses calculated classically. These realistic values should therefore be taken into account when modelling degradation (wear) and the generation of friction noises. Obviously, local relative velocities can lead to temperature increases, degradations of surfaces and to the production of the third body.

\section{Bibliographie}

Abendroth H., Wernitz B., «The integrated test concept: Dyno-vehicle, performance-noise», Technical Report 2000-01-2774, SAE, Warrendale, 2000.

Adams G.G., «Self-Excited Oscillations of Two Elastic Half-Spaces Sliding With a Constant Coefficient of Friction», Journal Applied Mechanics Reviews, 62, 1995, 867-872.

Adams G.G., «Steady Sliding of Two Elastic Half-Spaces Friction Reduction due to Interface Stick-Slip», Journal Applied Mechanics Reviews, 65, 1998, 470-475.

Akay A., «Acoustics of friction», Journal of the Acoustic Society of America, 111, 2002, $1525-1548$.

Baillet L., Berthier Y., Descartes S., «Modelling of the vibrations induced by friction. Experimental visualisation and identification of the relays between the first bodies and the third body», Proceedings of European conference on braking, Lille, 2002, 181-188.

Baillet L., Walter H., Brunet M., «A 3D contact algorithm for explicit dynamic F.E. code applied to the ironing process», Metal Forming, 2000, 141-147.

Baillet L., Sassi T., «Finite element method with Lagrange multipliers for contact problems with friction», Comptes Rendus Mecanique, 334, 2002, 917-922.

Baillet L., D’Errico S., Laulagnet B., Linck V., Berthier Y., «Finite Element Simulation of Dynamic Instabilities in Frictional Sliding Contact», accepted for publication in Journal of Tribology, 2005.

Baillet L., D’Errico S., Laulagnet B., «Understanding of the squealing noises appearance using a temporal finite element method», Accepted for publication in JSV, 2005.

Berthier Y., «Background on friction and wear», Lemaître Handbook of Materials Behavior Models, Academic Press, 2001, 676-699.

Bo L. C., Pavelescu D., «The friction - speed relation and its influence on the critical velocity of stick - slip motion», Wear, 82, 1982, 277-289.

Brockley C. A., Ko P. L., «Quasi - Harmonic Friction - Induced Vibration», ASME Journal of Lubrication Technology, 92, 1970, 550-556. 
Bundanov B. V., Kudinov V. A., Tolstoi D. M., «Interaction of Friction and Vibration», Soviet Journal of Friction and Wear, 1, 1980, 79-89.

Carpenter N.J., Taylor, R.L. Katona M.G., «Lagrange constraints for transient finite element surface contact», International Journal for Numerical Methods in Engineering, 32, (1991), 130-128.

Descartes S. and Berthier Y., «Rheology and flows of solid 3rd bodies: background and application to a MoS1.6 coating», Wear, 252, 2002, 546-556.

Godfey D., «Vibration reduced metal - to - metal contact and causes an apparent reduction in friction», ASLE, 10, 1967, $183-192$.

Ibrahim R. A., «Friction - induced Vibration, Chatter, Squeal, and Chaos, Part I: Mechanics of Contact and Friction», Applied Mechanics Reviews, 47, 1994, 209-226.

Ibrahim R. A., «Friction - induced Vibration, Chatter, Squeal, and Chaos, Part II: Dynamics and Modeling», Applied Mechanics Reviews, 47, 1994, 227-253.

Iordanoff I., Sève B., Berthier Y., Journal of Tribology, 124, (2002), 530-538.

Ko P. L., Brockley C. A., «The measurement of Friction and Friction - Induced Vibration», ASME Journal of Lubrication Technology, 92, 1970, 543-549.

Linck V., Baillet L., Berthier Y.. «Modeling the consequences of local kinematics of the first body on friction and on third body sources in wear», Wear, 255, (2003), 299-308.

Mills H.R., «Brake squeak», Institution of Automobile Engineers, 1938.

Moirot F., Nguyen Q.S., Oueslati A., «An example of stick-slip and stick-slip-separation waves», European Journal of Mechanics - A/Solids, 22, 2003, 107-118.

Nguyen Q.S., «Instability and friction, Comptes Rendus Mecanique, 331, 2003, 99-112.

Oueslati A., Nguyen Q.S., Baillet L., «Stick-slip-separation waves in unilateral and frictional contact», Comptes Rendus Mecanique, 331, 2003, 133-140.

Ranjith K., Rice J.R., «Slip dynamics at the interface between dissimilar materials», Journal of the Mechanics and Physics of Solids, 49, 2001, 341-361.

Rice J.R., Ruina A. L., «Stability of Steady Frictional Sliding», Journal of Applied Mechanics, 50, 1983, 343-349.

Simões F.M.F., Martins J.A.C., «Instability and ill-posedness in some friction problems», International Journal of Engineering Science, 49, 1998, 1265-1293.

Tolstoi D. M., «Significance of the normal degree of freedom and natural normal vibrations in contact friction», Wear, 10, 1967, 199-213.

Van De Velde F., De Baets P., «The friction force during stick - slip with velocity reversal», Wear, 216, 1998, 139 - 149. 